\title{
SYNTHESIS AND CHARACTERIZATION OF MODIFIED MESOPOROUS SILICA-IMOBILIZED Cu(II)-ACETONITRILE COMPLEX AND ITS APPLICATION IN TRANSESTERIFICATION OF FRYING OIL
}

\author{
Syukri *, Rycce Sylviana Pratikha, and Novesar Jamarun \\ Department of Chemistry, University of Andalas \\ * Corresponding author, tel/fax : 081374731406, email: syukri@fmipaunand.ac.id
}

\begin{abstract}
Mesoporous silica has attracted rapidly growing attention in catalysis. In this work, mesoporous silica was synthesized by using CTAB surfactant and then modified by $\mathrm{AlCl}_{3}$. Such material was used as support for $\mathrm{Cu}(\mathrm{II})$--acetonitile complex and applied in transesterification of frying oil. The XRD pattern of the obtained silica confirms the availability of chracteristic peak on silica surface while its TEM exhibits the uniformity of nanochannel of the mesoporous silica. The particle size of silica support has become smaller after grafting process showed by SEM images. FT-IR spectra of the materials indicated that the $\mathrm{Cu}(\mathrm{II})$ grafted on the mesoporous silica was in the form of its acetonitrile complex. Supprisingly, the $\mathrm{Cu}$ loading the grafted catalyst was found to be very high. That was $21 \%$, when the catalyst applied on transesterification of the examined frying oil the amount of total methyl ester yielded were of $65 \%$.
\end{abstract}

Keywords: mesoporous silica, $\mathrm{AlCl}_{3}, \mathrm{Cu}(\mathrm{II})$-acetonitrile complex, transesterification

\section{INTRODUCTION}

Highly ordered mesoporous silica in 1992 attracts rapidly growing attention in its application. MCM-41 as one member of M41s family from Mobile Corporation has been synthesized using CTAB as structure directing agent and confirm the uniform pore size $(2-50 \mathrm{~nm})$, tunable pore size, large surface area, high pore volume, and high thermal stability ${ }^{[1]}$. Their advantages have great interesting and promising field and potential to apply in catalysis, support ${ }^{[2]}$, and adsorbent ${ }^{[3]}$.

The important limitation of mesoporous silica is the lack of active site in it framework. Many researches have been reported to increase the potential application by incorporated other metals such as $\mathrm{Al}^{[4]}, \mathrm{B}^{[5-7]}$, $\mathrm{Ti}^{[8]}, \mathrm{Pd}-\mathrm{Au}^{[9]}$ to it framework and modification of silica surface with weakly coordinated anion $\mathrm{BF}_{4}^{-[10]}, \quad \mathrm{B}\left(\mathrm{C}_{6} \mathrm{~F}_{5}\right)_{4}^{-[11]}$,
$\mathrm{B}\left\{\mathrm{C}_{6} \mathrm{H}_{3}\left(\mathrm{~m}-\mathrm{CF}_{3}\right)_{2}\right\}_{4}{ }_{4}^{-}, \quad\left\{\left(\mathrm{C}_{6} \mathrm{~F}_{5}\right)_{3} \mathrm{~B}-\mathrm{C}_{3} \mathrm{H}_{3} \mathrm{~N}_{2-}\right.$ $\left.\mathrm{B}\left(\mathrm{C}_{6} \mathrm{~F}_{5}\right)_{3}\right\}, \mathrm{Al}\left\{\mathrm{OC}\left(\mathrm{CF}_{3}\right)_{3}\right\}_{4}^{-[12]}$ and $\mathrm{AlCl}_{3}{ }^{[13]}$. These ways attributed to improve thermal stability and active site in mesoporous silica.

$\mathrm{Cu}(\mathrm{II})$-acetonitrile complex has employed in catalytic process. Syukri et al reported $\mathrm{Cu}$ (II)-acetonitrile complex potential to enhance in cyclopropanation reaction ${ }^{[2,14]}$. It's complex confirm poor efficiency for economic and environmental due to recyclability, reuse, and regeneration of homogeneous catalysts isn't applicable. And the great attempt have been done a immobilization of homogeneous catalyst in support material t. In our previous work, modified silica was synthesized with $\mathrm{AlCl}_{3}$ in surface silica via electronic interaction and potential to applied in transesterification reaction $^{[13]}$. In this work, mesoporous silica as supported material was modified by $\mathrm{AlCl}_{3}$ and then was immobilized by complex of $\mathrm{Cu}(\mathrm{II})$-acetonitrile. Mesoporous silica and the 
grafted catalyst was characterized by FT-IR, XRD, SEM, TEM, and AAS. This catalyst obtained was then applied in transterification of frying oil. Frying oil confirm the pure oil that contains low free fatty acid.

\section{EXPERIMENTAL SECTION}

\section{Materials}

The following materials, Sodium silicate $\left(\mathrm{Na}_{2} \mathrm{SIO}_{3}\right.$ : MERCK), CTAB $\left(\mathrm{C}_{19} \mathrm{H}_{42} \mathrm{BrN}\right.$ : MERCK), acetic acid glacial $\left(\mathrm{CH}_{3} \mathrm{COOH}\right.$ : MERCK), hydrochloric acid $37 \%$ ( $\mathrm{HCl}$ : MERCK $)$, aniline $\left(\mathrm{C}_{6} \mathrm{H}_{5} \mathrm{NH}_{2}:\right.$ MERCK), toluene $\left(\mathrm{C}_{6} \mathrm{H}_{5} \mathrm{CH}_{3}:\right.$ MERCK $)$, aluminium trichloride $\left(\mathrm{AlCl}_{3}\right)$, copper sulphate $\left(\mathrm{CuSO}_{4}\right)$, aquadest, methanol, frying oil were used without purification for the synthesis of the grafted catalyst.

\section{Instrumentation}

Mesoporous silica and the obtained catalyst were characterized by XRD, FTIR, SEM, TEM, and BET. Copper contain in grafted catalyst was analysed by AAS and methyl ester formation as a product of reaction was followed by GC-MS.

\section{Procedure}

\section{Synthesis of mesoporous silica}

We have prepared mesoporous silica with follow the molar ratio $1 \mathrm{SiO}_{2}: 0.27 \mathrm{CTAB}$ : $60 \mathrm{H}_{2} \mathrm{O}$ [14]. In a typical synthesis, 49.20075 g CTAB was dissolved in $270 \mathrm{~mL} \mathrm{H}_{2} \mathrm{O}$. $45.2088 \mathrm{~mL} \mathrm{Na}_{2} \mathrm{SiO}_{3}$ in $\mathrm{H}_{2} \mathrm{O}$ was added dropwise under stirring, $\mathrm{pH}$ adjusted at 11 by adding $\mathrm{CH}_{3} \mathrm{COOH}$, stirred for $24 \mathrm{hs}$ and aged for $16 \mathrm{hs}$. The resulting gel is transferred into polyethylene bottle and followed hydrothermal treatment at $373 \mathrm{~K}$ for 3 days. The obtained solid was washed with aquadest and dried at $373 \mathrm{~K}$ for $24 \mathrm{hs}$. The powder was extracted with acidified methanol for 3 hs to remove surfactant in mesoporous silica. The obtained solid product was washed by aquadest/methanol and dried at $373 \mathrm{~K}$ for 24 hs and white powder formed.

\section{Synthesis of modified mesoporous silica}

Mesoporous silica was mixed with aniline (toluene) and stirred for 24 hs. Anhydrous aluminium trichloride was added into the mixture. The resulting suspension was filtered, washed with toluene, and dried at room temperature. Solid obtained was grayish colours.

\section{Synthesis of grafted catalysts}

Modified silica, anhydrous $\mathrm{CuCl}_{2}$, and acetonitrile were starting materials for synthesis of the catalyst. Starting materials were mixed and stirred for $24 \mathrm{hs}$ and washed with acetonitrile, and dried at room temperature. The catalyst obtained were characterized by FTIR, XRD, SEM, BET, and TEM.

\section{Catalytic activity test of grafted catalyst on} frying oil transesterification

The amount of 1 weight $\%$ of catalyst was respectively added to methanol and stirred $\left(300 \mathrm{rpm}, 60{ }^{\circ} \mathrm{C}\right.$ ) for 15 minutes. Afterward, frying oil was put into catalysts-methanol solution and stirred for $3 \mathrm{hs}$. The solution was analyzed by GC-MS. Yield of methyl ester product was accounted as in equation 1 .

\section{RESULTS AND DISCUSSION}

\section{XRD Analysis}

Figure 1 displays the wide angle XRD pattern of silica which observed at $22.35^{\circ}$. Its observed the main characteristic of silica (ICDS \#75303). Grafting of complex Cu(II)acetonitrile in silica shows the decreasing intensity of peak, broadening, and shift to higher $2 \theta$ and attribute the grafting metal complexes in inside the channels of mesoporous silica and also indicate the disorder of framework of silica.

$$
\text { yield of products }=\frac{\text { peak area } \times \text { volumes of methyl ester produced } \times 100 \%}{\text { volumes of oil taken for the reaction }}
$$




\section{FT-IR Analysis of The Grafted Catalyst}

The IR technique was employed to identify the formation of grafted catalyst on the bands characterisitic.

FTIR spectra in Figure 2 showed bands at $1085 \mathrm{~cm}^{-1}$ and $794 \mathrm{~cm}^{-1}$ observed stretching vibrations of $\mathrm{Si}-\mathrm{O}-\mathrm{Si}$ framework. The stretching band at $3434 \mathrm{~cm}^{-1}$ characteristic $\mathrm{OH}$ groups from adsorbed water and silanol groups in mesoporous silica and additional bands at $461 \mathrm{~cm}^{-1}$ due to their deformation of $\mathrm{Si}-\mathrm{O}$ bonding from $\mathrm{SiO}_{4}$. Band at $797 \mathrm{~cm}-1$ revealed that $-\mathrm{O}-\mathrm{H}$ bending from $\mathrm{Si}-\mathrm{OH}$. Present band at $2927 \mathrm{~cm}^{-1}$ prove that the methyl groups from surfactant. Modification of surface mesoporous silica with $\mathrm{AlCl}_{3}$ attributed stretching vibrations of $\mathrm{Si}-\mathrm{O}-\mathrm{Si}$ at $960 \mathrm{~cm}^{-1[15]}$.

\section{Morphology Surface Analysis}

The morphology for mesoporous silica are detected by scanning electron microscopy. Images of mesoporous silica and grafted sample are shown in Figure 3.

Mesoporous silica samples exhibit smooth surface silica and the TEM images in Figure 4 showed the uniform morpholgy of mesoporous silica and found the nanometer scale of particle. While grafted catalyst showed the irreguler shape particle. Irreguler particle revealed with XRD in figure 1 that lower crystallinity and disorder of particle will be occur after grafting complex.

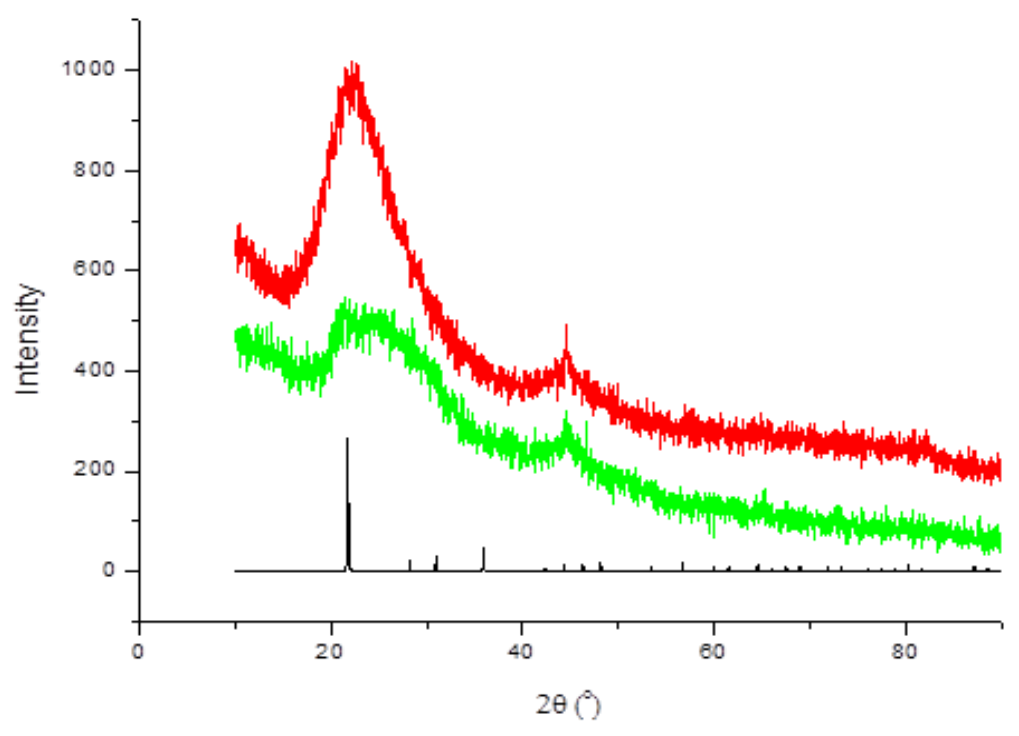

Figure 1. XRD pattern of (a) mesoporous silica (b) grafted catalyst.

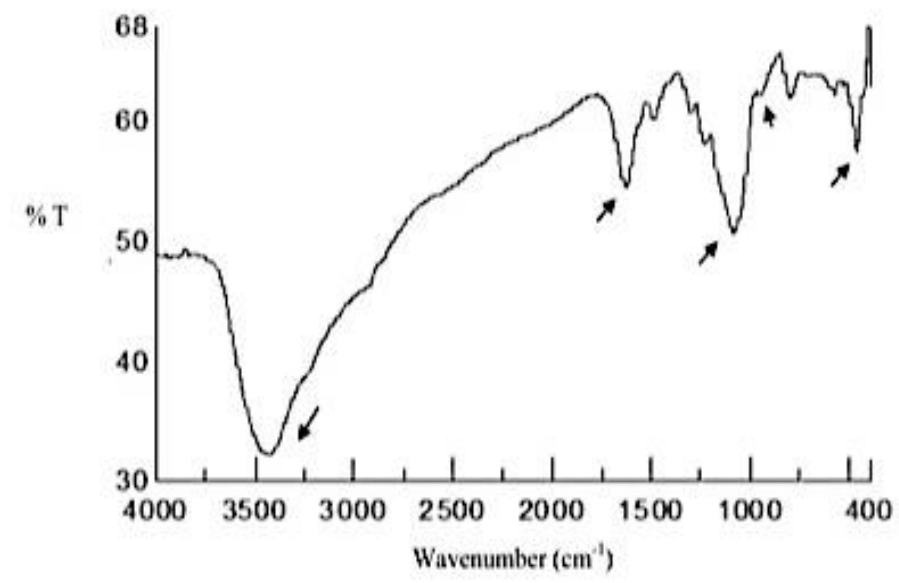

Figure 2 Spectra of grafted catalyst. 


\section{BET}

Mesoporous silica exhibits isotherm type IV (IUPAC) that it confirm the hysteresis loop of mesoporous silica in figure 5. Monolayer adsorption in pore wall was followed capillar condensation at $\mathrm{P} / \mathrm{P}^{\mathrm{o}} 0,7-0,85$. Pore diameter of mesoporous silica obtained was $7.05 \mathrm{~nm}$. Its confirm the mesoporous silica was obtained using CTAB as molecular templating agent.

\section{AAS Analysis}

Copper metal loading in grafted catalyst was analyzed by AAS and found $21,32 \% \mathrm{Cu}$ content in catalyst. In our previous work, using modified silica gel as support which have micrometer size only found $6.19 \% \mathrm{Cu}$ in catalyst [13]. Higher content of metal loading was influenced by the amount of silanol groups in surface. Mesoporous silica has larger surface area than silica amorphous and surely, the amount of silanol groups can be increased.

\section{Catalytic Activity of Grafted Catalyst}

Yield of methyl ester in grafted catalyst found $65,24 \%$ of product that it contain hexadecanoic acid methyl ester $(31.16 \%)$, octadecanoic acid methyl ester (3.18\%), 9octadecenoic acid methyl ester (32.40\%), and 9,12-octadecadienoic acid methyl ester
(3.62\%) in Figure 6. The increasing of metal loading can increase the yield of product due to the active site of catalyst and larger surface area.
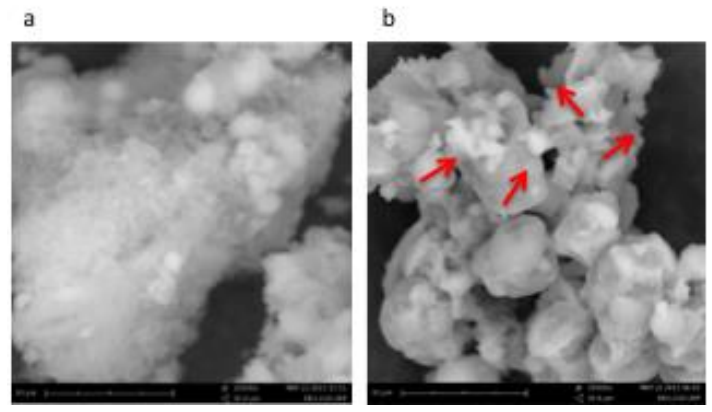

Figure 3 SEM images of (a) mesoporous silica (b) grafted catalyst.

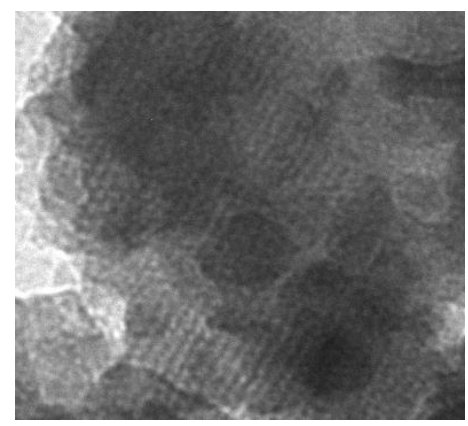

Figure 4 TEM images of mesoporous silica.

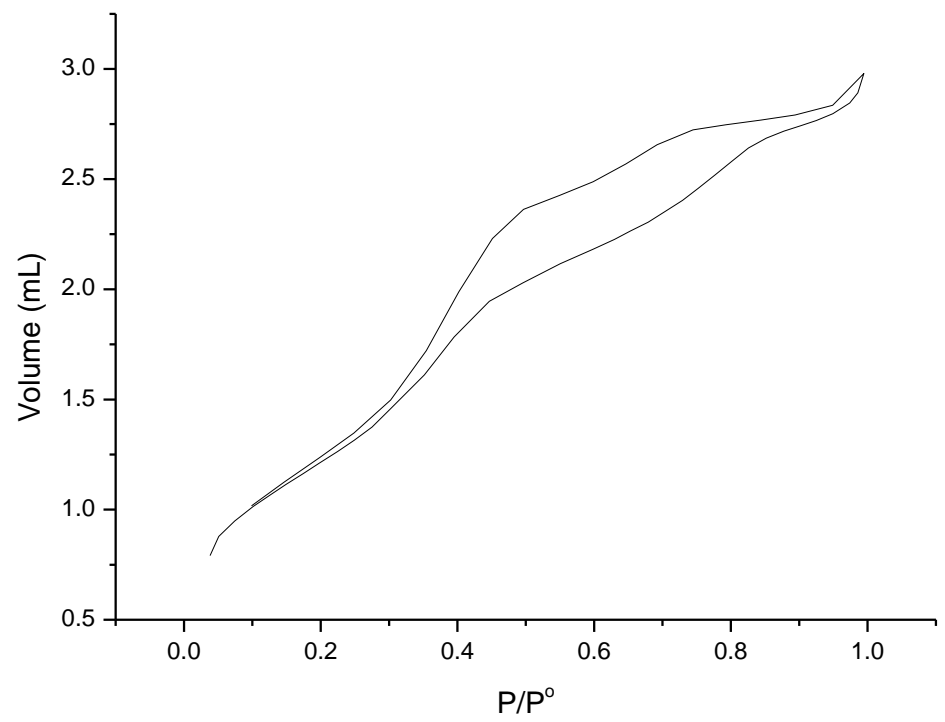

Figure 5. $\mathrm{N}_{2}$ adsorption-desorption of mesoporous silica. 


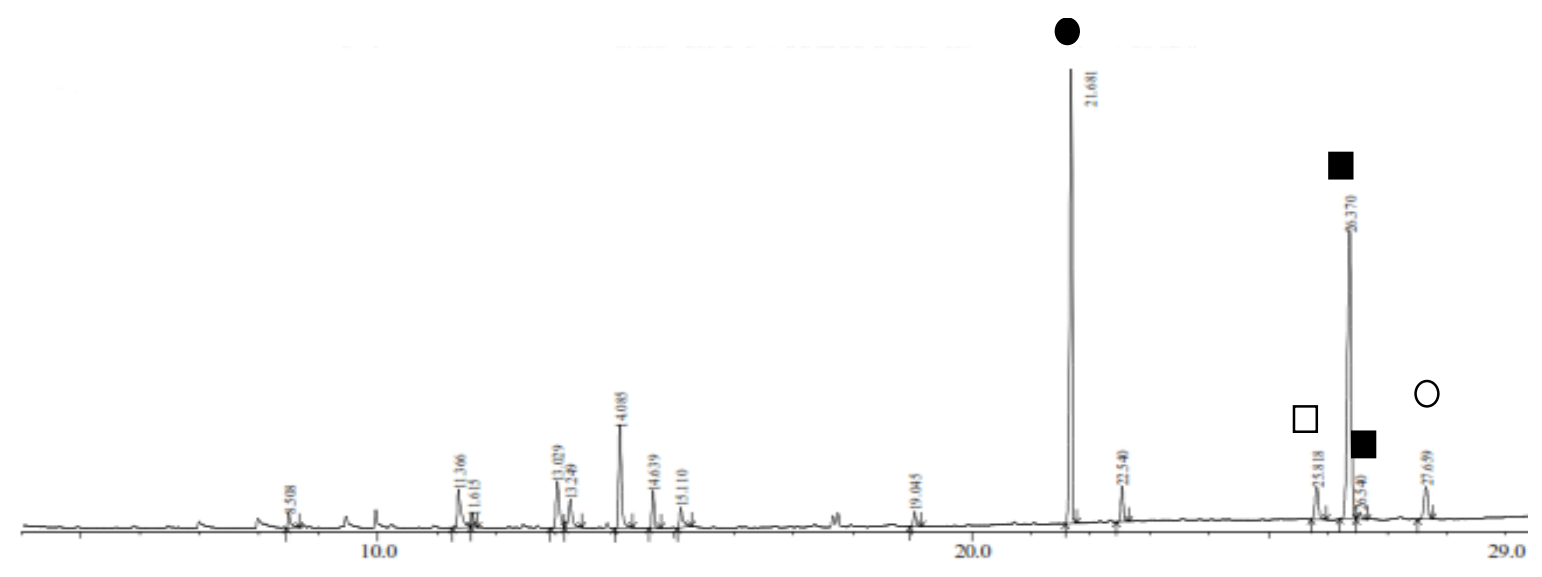

Figure 6. Chromatogram of product acatalytic activity grafted catalyst.

\section{CONCLUSION}

The mesoporous silica is the one of candidate a support material in catalyst. Mesoporous silica obtained has the pore diameter about 7 $\mathrm{nm}$. Using mesoporous silica as support can increase the metal loading cotent and catalytic activity. The catalyst obtained exhibit good catalytic activity which $21 \% \mathrm{Cu}$ contain was found $65 \%$ of product.

\section{ACKNOWLEDGEMENTS}

Authors thank specially to LLPM of Andalas University for financial support by SIMLITABMAS project. All colleagues are also appreciated for their assistance on this work.

\section{REFERENCES}

1. M. Hoffmann, M. Cornellius, J. Morrel, and Fröba., Silica-Based Mesoporous Organic-Inorganic Hybrid Materials, Angew. Chem. Int, 45, 3216-3251, (2006).

2. S. Syukri, C. E. Fischer, Al-Hmaideen, A., Li, Y., Zheng, Y., Kühn, F. E., Modified MCM 41 supported acetonitrile ligated copper(II) and its catalytic activity in cyclopropanation of olefins, Micro. and Meso, 113, 171177, (2008)

3. K. Dimos, P. Stafni, M.A. Karakassides, and Y. Deligiannakis, Synthesis and characterization of hybrid MCM-41 materials for heavy metal adsorption,
Micro and Meso Mat, 126, 65-71, (2009).

4. E. Kaya, N. Oktar, G. Karakas, and K. Murtezaoğlu, Synthesis and Characterization of Ba/MCM-41, Turk. J. Chem, 34, 935-943, (2010).

5. K. Fang, J. Ren, and Y. Sun, Synthesis and characterization of steam-stable AlMCM-41, Mat. Chem. \& Phy, 90, 1621, (2005).

6. W.S. Chae and Y.R. Kim, Structural confinement effects of ternary chalcogenide in mesoporous ALMCM41 of different pore diameters, J. Phys. Chem B, 107, 1585-1591, (2003).

7. A.I. Carrilo, E. Serrano, J.C.S. Ruiz, R. Luque, and J.G. Martinez, Helical Aland Ce-MCM-41 materials as novel catalyst for acid and redox processes, Appl. Cat A: General, 435-436, 1-9, (2012).

8. S. Wang, Y. Shi, and X. Ma, Microwave synthesis, characterization and transesterification activities of Ti-MCM41Micro. \& Meso. Mat, 156, 22-28, (2012).

9. X. Yang, D. Chen, S. Liao, H. Song, Y. $\mathrm{Li}, \mathrm{Z}$. Fu, and Y. Su, High-performance $\mathrm{Pd}-\mathrm{Au}$ bimetallic catalyst with mesoporous silica nanoparticles as support and its catalysis of 
cinnamaldehyde hydrogenation $J$. Cat, 291, 36-43, (2012).

10. A. Sakthivel, S. Syukri, A.K. Hijazi, and F.E. Kühn, Heterogenization of $\left[\mathrm{Cu}\left(\mathrm{NCCH}_{3}\right)_{4}\right]\left[\mathrm{BF}_{4}\right]_{2}$ on mesoporous AlMCM-41 / AlMCM-48 and its application as cyclopropanation catalyst, Cat. Let, 111, 43, (2006).

11. A.K. Hijazi, A. Al-Hmaideen, S. Syukri, N. Radhakrishnan, E. Herdtweck, B. Vort, and F.E. Kühn, Synthesis and Characterization of Acetonitrile Ligated Transition - Metal Complexes with Tetrakis (pentafluorophenyl) borate as Counteranions, Eur. J. Inorg. Chem, 2892-2898, (2008).

12. Y. Li, B. Diebl, A. Raith, and F.E.Kühn, Syntheses of acetonitrile ligated copper complexes with perfluoroalkoxy aluminate as counter anion and their catalytic application for olefin aziridination Tetrahedron Let, 49, 5954-5956, (2006).
13. R. S. Pratikha, Syukri, and Admi., Synthesis and characterization of acetonitrile ligated cu(ii)-complex and its catalytic application for transesterification of frying oil in heterogeneous phase, Indo. J. Chem, 13, 1, 72-76, (2013).

14. S. Syukri, A.K. Hijazi, A. Sakthivel, A. Al-Hmaideen, and F.E. Kühn, Heterogenization of Solvent-Ligated Copper (II) Complexes on Poly(4vinylpyridine) for the Catalytic Cyclopropanation of Olefin, Inorg. Chim. Acta, 360, 197-202, (2007).

15. K.D. Pandiangan, I.G. Suka, M. Rilyanti, S. Widiarto, D. Anggraini, S. Arief, and N. Jamarun, Karakteristik keasaman katalis berbasis silika sekam padi yang diperoleh dengan teknik solgel, Proc. Nat. Conf. Sci. Technol II, Lampung University, 17-18 November (2008). 